\title{
The Cubing Technique: A Technique in Pre-Writing to Improve Students' Writing Skill
}

\author{
Suhaimi $^{1 *}$, Mukhaiyar ${ }^{2}$, M. Zaim ${ }^{3}$, and Azwar Ananda ${ }^{4}$ \\ ${ }^{1}$ Doctorate Program Student of Education Science Program, Padang State University \\ ${ }^{234}$ Graduate program of Padang State University \\ *Corresponding author. Email: suhaimi.kerinci@gmail.com
}

\begin{abstract}
In the context of teaching writing, students are required to get better result in writing any kinds of text. However, students are still encountered problems in writing, such as not all writing stages are done. Specifically, students did use a certain technique on the prewriting stage. Therefore, they easily faced problems in producing and organizing ideas, and developing them into good paragraphs. Therefore, the researcher conducted research concerning the use of the cubing technique in order to improve students' writing skill. This research is an action research. The participants of this reserach was 4A class of the fourth semester of IAIN Kerinci. This research employed two kinds of data collection techniques; quantitative and qualitative data collection techniques. The findings showed that the cubing technique improved students' writing skill. It can be seen from the result of students' writing. It can be seen from the increasing of students' score in cycle I, cycle II, and cycle III. Based on those findings, it was concluded that the students' writing skill got improvement through the cubing technique.
\end{abstract}

Keywords: Writing, The cubing technique, Pre-Writing

\section{INTRODUCTION}

Learning English includes learning the four skills; listening, speaking, reading, and writing. Writing is as one of the important skills which have to be mastered by university students. They are expected to be able to write their paper assignment, articles, and a thesis as the requirements to finish their studies. Particularly, in learning English, the students are expected to be able to produce their writing in English. Thus, it needs good efforts for teachers and students to improve students' writing ability. The teachers have to teach English through the appropriate technique, while students have to apply that technique in the writing process to improve their writing skill. Then, teachers and students have to understand and go through to all stages of writing process. Writing is not only as the activity of exploring and write ideas without having the phase of collecting and organizing ideas, writing, editing, and revising. Writing is a complex process that allows writers to explore thoughts and ideas and make them visible and concrete. Gaith [1] writing also encourages thinking and learning to motivate communication and make thought available for reflection. Then, Writing is a combination of process and product. Sokolik in Linse [2] the process of writing is starting by collecting ideas to produce good quality of writing final product. Linse [3] the process of writing involve pre-write, write, revise, edit and publish.

Based on our experience in teaching writing, it was found that the students dealt with some problems in writing. Actually, the students have many ideas, but they could not express and organize their ideas clearly. In other words, their ideas jump up and down, thus, the topic of their writing were not developed in good supporting details [4]. Another problem is the students did not understand well how to identify and organize their ideas which closely related to the topic and text type of writing. They found difficulties to decide whether their ideas were appropriate to develop as supporting details in their paragraph. Of course, they have to choose and decide the ideas of their supporting details based on the topic and type of paragraph writing. It is also as one of their problems in writing. The lack of vocabulary and errors in mechanics were also students' problems in writing. Basically, there are many techniques that can be used by the teachers, of course, in order to help students to develop their writing skill. Those techniques may be applied in prewriting stage since prewriting is the important stage in the writing process. Seow in Liu [5] prewriting can be claimed as the importance step in writing. It helps students stimulate thoughts for getting started. In fact, it moves students away from having to face a blank page to generating tentative ideas and gathering information for writing 
Based on the result of interview with the fourth semester students of English Department of IAIN Kerinci, it was known that how to explore the ideas and develop the paragraph in good order based on text type of writing was as the students' problem in writing. They argued that they have ideas to develop their paragraph, but they do not know how to explore them in good sequence based on the topic and type of paragraph. In addition, they said that they had lack of vocabulary in writing. Thus, it was found that the students just had blank piece of paper in some minutes after asking them to write a paragraph. It was hard for them to start writing. Then, their final product of writing contained of jump up and down ideas. Their writing was not presented in good unity and coherence. They claimed that they did not understand and do pre - writing stage of writing process. They argued that after getting a topic of writing, they did free writing to explore their ideas and they submitted their writing as final product. In other words, they did not go through to all stages of writing process. Specifically, they did not start writing in pre - writing stage to collect their ideas. In this stage, one of the writing techniques can be used to make easy in collecting and organizing ideas. It can be concluded that the cubing techniques can help students identify ideas about topics. Therefore, the researchers are interested to use the cubing technique in teaching writing to improve students' writing skill.

\section{Related Work}

Sokolik in Linse [6] notes that writing is a combination of process and product. The process refers to the act of gathering ideas and works with them until they are presented in a manner polished and comprehensible to readers. "The process writing approach involves the process-steps necessary to produce a good quality final piece of writing. Linse [7] "it includes the steps of writing process: pre-write, write, revise, edit and publish". Bello [8] states that the writing processusually begins with some form of prewriting activity in which learners work together in groups to generate ideas about a particular topic. Oshima [9] "Prewriting is a way to get ideas". The process of writing includes some stages which are started with the collecting of ideas and develop them in order to produce in final piece of writing and can be presented to the reader. There are four stages in writing process, namely prewriting, writing, revising, editing and publishing. Cubing technique is a technique that uses in prewriting stage, which offers a more systematic method of asking questions and generating ideas. Scott [10] by using this technique, a writer can explore his ideas and develop through cubing guidelines In this case, a writer often cannot go on writing about a subject because they are locked in on a single way of looking at the topic, and that's where cubing works well. Dawson [11] "Cubing allows a writer to explore various aspects of a topic, forcing the writer to think and re - think the topic" Beside that, Cwiklinski [12] states a writer can apply cubing to the main person, thing, or concept that the writing will be about. In addition, cubing can also be applied for an abstract concept and it can be used in all disciplines.

In Academic Center article [13], it notes "cubing is a technique that encourages the writer to explore different aspects of a topic. Essentially, the writer answers six commands or prompts". Furthermore, by using the cubing technique, the students can look at different perspectives from six approaches of the cubing technique as proposed describing, comparing, associating, analyzing, applying, and arguing for it Furthermore, some reserach also were conducted related to the cubing technique. Resi, et.al did a research and found that the cubing technique is highly effective to teach writing recount text. The the cubing technique also eased students to develop and organize ideas. Furthermore, Beacon [14] noted that the application of the cubing technique in writing narrative improves the students' achievement in writing narrative. In addition, Dibello [15] showed that EFL learners, especially those at the tertiary level and English teachers can use the cubing technique to write and develop their ideas into written products

\section{RESEARCH METHOD}

This research concerns on the use of the cubing technique to improve students' writing skill. This is a classroom action research (CAR). In this research, it is related to the concept of improving the students' writing by the cubing technique. In this case, the teacher as the researcher who identifies the learning problems and did the certain action in order to solve those problems to improve the student's writing skill. This research carried out in English Department of IAIN Kerinci. It was conducted at English Department of IAIN Kerinci. The participant of this research were students in $4 \mathrm{~A}$ of the fourth semester classes of English Department students of IAIN Kerinci who take writing II course. In this research, there were two types of data; quantitative data and qualitative data. Quantitative data was used to analyze to what extent the cubing technique can improve students' writing skill of the fourth semester English Department students of IAIN Kerinci. Quantitative data were taken from the results test which was given to the students. Then, qualitative data was used to analyze what factors influence the improvement of the fourth semester students' writing skill in English Department of IAIN Kerinci. Quantitative instrument 
was test. Test was as the instruments that used to get students' score at the end of every cycle. Meanwhile, qualitative instruments involve researcher as the key instruments, observation sheet, interview guide. In this case, quantitative data was obtained by giving test, then, qualitative data was collected through observation and interview. Then, quantitative data was analyzed by using statistical technique and qualitative data was analyzed by using descriptive interpretative technique.

\section{RESULT}

\section{The Results of Cycle I}

In the last meeting of the cycle I, the teacher directly asked the students to write a descriptive paragraph with their own topic. Fortunately, the result of students' writing in the last meeting of cycle I showed the improvement of students' writing ability. It was higher than the first meeting of cycle I. Table 1 shows the score distribution in the cycle I.

From the table 1, it can be seen that in the first meeting of cycle I, six students $(33,33 \%)$ were in fair category, and twelve students $(66,67 \%)$ were in weak category. Meanwhile, in the last meeting of cycle I, six students $(26,08 \%)$ ten students $(55,55 \%)$ were in fair category, and eight students $(44,44 \%)$ were in weak category. Based on the data above, it can be seen that there was an improvement of students' writing skill in the cycle I. In fact, the result of students' writing in the last meeting of cycle I was higher than the first meeting. Based on the result of interview with some students who were weak in the first meeting and fair in last meeting, they argued that by having and applying the cubing technique to make an outline of their writing, they thought that writing was not difficult since they had guideline in developing their paragraph. They said that by combining their explanation in six approaches of the cubing technique, they had a paragraph. It was interesting

Table 1. The distribution of scores in the Cycle I

\begin{tabular}{|c|c|c|c|c|c|}
\hline \multirow{2}{*}{ Score Interval } & \multirow{2}{*}{ Category } & \multicolumn{2}{|c|}{ The first meeting } & \multicolumn{2}{c|}{ The last meeting } \\
\cline { 3 - 6 } & & Frequency & $\%$ & Frequency & $\%$ \\
\hline $17-20$ & Very good & - & - & - & - \\
\hline $13-16$ & Good & - & - & - & - \\
\hline $9-12$ & Fair & 6 & $33,33 \%$ & 10 & $55,55 \%$ \\
\hline $5-8$ & Weak & 12 & $66,67 \%$ & 8 & $44,44 \%$ \\
\hline $0-4$ & Poor & - & - & - & - \\
\hline
\end{tabular}

Table 2. The distribution of scores in the Cycle II

\begin{tabular}{|c|c|c|c|c|c|}
\hline \multirow{2}{*}{ Score Interval } & \multirow{2}{*}{ Category } & \multicolumn{2}{|c|}{ The first meeting } & \multicolumn{2}{c|}{ The last meeting } \\
\cline { 3 - 6 } & & Frequency & $\%$ & Frequency & $\%$ \\
\hline $17-20$ & Very good & - & - & - & - \\
\hline $13-16$ & Good & - & - & 6 & $33,33 \%$ \\
\hline $9-12$ & Fair & 10 & $55,55 \%$ & 8 & $44,44 \%$ \\
\hline $5-8$ & Weak & 8 & $44,44 \%$ & 4 & $22,22 \%$ \\
\hline $0-4$ & Poor & - & - & - & - \\
\hline
\end{tabular}

\section{The Results of Cycle II}

In the last meeting of cycle II, the students work individually to produce their own final contrast or comparison paragraph of their own topic. They were free to choose the topic of their writing. It was done to make students could express their ideas and develop their paragraphs based on their own interesting topic. They might also chose easy topic for them to develop into the paragraph. Based on the result of students' writing, it was found that some of the students got improvement in their writing. It can be shown in the table 2 .

Based on the data collected, it was found that the students had good improvement in their writing. In fact, it can be seen that in cycle I, no students were in good category. In cycle II, it showed that six students were in very good category. The students could produce an paragraph based on the topic given well. They could develop their writing in good composing, style, sentence formation, usage, and mechanics. Based on the result of observation, it was found that the students did not only focus on combining their ideas into good paragraph based on the six approaches of the cubing technique. In this cycle, they checked their grammar and vocabulary used when they were collecting and organizing their ideas in pre-writing stage. In fact, the students used the cubing technique in pre - writing stage to collect and organize their ideas by using appropriate grammar and 
vocabulary. They understood what type of grammar used and appropriate word choice to make comparison or contrast paragraph. Thus, they could get their final product of writing in correct grammar and vocabulary.

\section{The Results of Cycle III}

In cycle III, the activities were focused on students' writing practice. In the first meeting of cycle III, the students worked in pairs to produce descriptive paragaraph. They used the cubing technique in their pre - writing stage. They also chose the topic of their writing freely. Most of them wrote a descriptive paragraph about a place. After producing their paragraph, they did peer assessment. One group had to give comments and correction to another group's paragraph. Similarly, in the second meeting of cycle III, the students were asked to write a comparison and contrast paragraph in pairs, then, other groups gave comments or corrections. The comments and correction were given to both of their final product of writing and the ways their collect their ideas through the cubing technique. Moreover, in the fourth and fifth meetings of cycle III, the students were asked to write a descriptive and comparison or contrast paragraph individually. They were free to choose the topic of their writing. Then, they also got peer assessment towards composing, style, sentence formation, usage, and mechanics of their writing. Based on the results of observation, it was found that the students were interesting in finishing their task and they could finish their writing easily. The following table shows the improvement of students' writing in cycle I, II, and III.

Table 3. The distribution of scores in the Cycle I, II, and III

\begin{tabular}{|c|c|c|c|c|c|c|c|}
\hline \multirow{2}{*}{ Score Interval } & \multirow{2}{*}{ Category } & \multicolumn{2}{|c|}{ Cycle I } & \multicolumn{2}{c|}{ Cycle II } & \multicolumn{2}{c|}{ Cycle III } \\
\cline { 3 - 8 } & & F & $\%$ & F & $\%$ & F & $\%$ \\
\hline $17-20$ & $\begin{array}{c}\text { Very } \\
\text { good }\end{array}$ & - & - & - & - & 10 & 55,56 \\
\hline $13-16$ & Good & - & - & 6 & 33,33 & 5 & 27,77 \\
\hline $9-12$ & Fair & 10 & 55,55 & 8 & 44,44 & 3 & 16,67 \\
\hline $5-8$ & Weak & 8 & 44,44 & 4 & 22,2 & - & - \\
\hline $0-4$ & Poor & - & - & - & - & - & - \\
\hline
\end{tabular}

Based on the table 3 above, it can be seen that the students' writing got improvement. In fact, in cycle I, eight students were in weak category, while in cycle III no one got weak category. Fortunately, ten students got very good in cycle III. Most of the students were able to produce their writing in good style, usage, and mechanics. Then, they organized their ideas in systematic ways since the use the cubing technique could help them to collect and arrange their ideas.

\subsubsection{The factors of students' writing improvement}

Based on data collection, it was found some factors which influenced the students' writing skill. Those factors involved classroom management, teaching and learning time, teaching and learning media, reading material, and learning method. For further detailed of each factor, it was described as follow:

1). classroom management

In teaching and learning process of writing, the ways how to manage classroom is very important. It was one of the factors which influenced students' writing skill. In this case, the students really needed comfortable atmosphere since they had to be focused on collecting ideas then developing them into good final product of writing. Thus, the classroom had to be managed systematically in the case of the teacher gave explanation then the students explored their understanding, collected ideas, and finished their writing through every stage of writing process.

2). Teaching and learning time

Writing class was done in the morning. It was good time of learning process for students. Based on the results of interview with some students, they argued that they were interested in writing in the morning. They had full of morning spirit, good mood, and energetic, so it was easy for them to collect ideas and made good writing product. Learning time influenced how the quality of students' the writing processand product were. In fact, having writing class in the morning was an appropriate time for getting good students' writing. It was also the factor which influenced students' writing. 3). teaching and learning media

Media was also one of the factors which influenced students' writing skill. The use of interesting and appropriate media gave good contribution for students to collect and develop their ideas instead of only for presenting writing materials. Before asking students to do writing process, they were presented writing materials; parts of a kind of writing and its example. Those materials were presented by using in focus to make materials are presented systematically and clearly to whole class. The use of pictures were found in writing process; in the pre writing stageas the way for students to collect ideas more easily. Then, the 
students were also asked to use different color of pens to make their writing more interesting and easier to identify their writing part.

4). Reading material

Another factor which influenced students' writing skill was reading material. Based on data collected, it was found that asking students to find sources and read them before writing gave good contributions towards students' writing. The students had more information related to the topic, so it was for them to organize and develop their ideas into good writing product.

\section{e). Learning method}

Learning method is also one of the factors which influenced students' writing skill. How to teach writing through the cubing technique influenced how the students produced their own writing individually. By giving clear explanation and good example of six approaches of the cubing technique have good contributions for the students in developing their writing systematically. The students argued that they had good guideline to develop their writing based on their statements in each approach of the cubing technique, thus, it was easy for them to organize and develop their writing systematically.

\section{DISCUSSIONS}

Based on the data collection, it was found that the students got improvement in their writing by using the cubing technique in their pre - writing stage. The cubing technique has six approaches that can be guideline for students to start writing. Their paragraph can be developed through their answers or statements in six approaches of the cubing technique. It was very helpful for the students since they could organize their ideas systematically. By comparing the result of students' writing in cycle I, cycle II, and cycle III, it showed that there was improvement from the students' writing score. It was seen that the result of students' writing in cycle II was better than cycle I and the result of cycle III was better than cycle I and II. Furthermore, in the first cycle, students faced problems in collecting their ideas and they were unfamiliar with the cubing technique, the ways how to apply them in writing process. Another problem was the students made mistakes in grammar and vocabulary. In cycle II, fortunately, the students got improvement in their writing. They were guided how to express their ideas through the cubing technique. The students got comments to their writing and corrections to their writing mechanics from their writing draft to their final product. Finally, in cycle III, the students showed their good improvement in their writing. They have used the cubing technique in many times of teaching meetings, so they have been able to apply it in teaching process. In line with the implementation of the cubing technique in pre - writing stage, the students had shown their writing habits to implement the cubing technique, so their writing ability were improved. By using the cubing technique, the students had to state their responses clearly through six approaches of the cubing technique. Thus, it could guide them to develop their paragraph systematically. Furthermore, the cubing technique also proposed the students clear usage and mechanics of their writing. In this case, starting in pre - writing stage, the students had clear correction towards the use of grammar, vocabulary, spelling, and punctuation of their writing by answering or giving statements towards six approaches of the cubing technique. The composing and style of their writing were also developed in good unity and coherence since they had arranged their ideas in good order through the implementation of the cubing technique in pre - writing stage. Specifically, in developing descriptive paragraph, the students had good organization of their paragraph. They started by giving general description in term of describing approach of the cubing technique. Then, they developed their paragraph by stating their ideas in others approach of the cubing technique; comparing, associating, analyzing, applying, and arguing for it or against. Similarly, to develop comparison or contrast paragraph, the students also did pre - writing through the cubing technique. They described in general what were compared or contrasted. Then, the paragraph was developed by giving detailed information or explanation in line with comparing, associating, analyzing, applying, and arguing for it or against. Thus, the students had clear guideline to write a certain type of paragraph. Their ideas were stated clearly and arranged systematically by implementing the cubing technique. Furthermore, the students' writing could be presented in good unity and coherence through developing their own statements or responses of six the cubing technique approaches. The use of the cubing technique actually has been researched in teaching writing at high schools level. Those researches were conducted in teaching writing some kinds of text types. As Lenuex [16] used the cubing technique to teach recount text in Junior High School students. Similarly. Peha [17] also used the cubing technique to teach descriptive and narrative texts. Then, the findings of all those researches found that the cubing technique give good effects and contributions in improving students' writing ability.

\section{CONCLUSION}

Based on the result of the research, the use of the cubing technique in the pre writing stage improved students' writing skill. The students' writing skill got 
improvement. It could be seen that there was the differences in students' writing score between cycle I, cycle II, and cycle III. The students could organize and developed their writing systematically through six approaches of the cubing technique. Others researcher are suggested to conduct research concerning the use of the cubing technique or how the implementation of cubing technique in others English skill. Then, English teachers were also suggested to use cubing technique in teaching writing or others English language skill.

\section{ACKNOWLEDGMENT}

Thank you for the Allah (Praise be unto Thee the Almighty), the prophet Muhammad (May Allah bless him and give him peace), parents, family, collaborators, and all of people who has been contributed in completing this research that cannot be mentioned one by one. Without any prayers, suggestions, criticisms, supports, and helping from a lot of people the researchers can not only do the research well but also never complete it.

\section{REFERENCES}

[1] G, Ghazi. The Nature of the Writing Process. 2002. DOI: http://nadabs.tripod.com/ghaith-writing.html

[2] L, Caroline T. Practical English Language Teaching: Young Learner. 2005

[3] L, Caroline T. Practical English Language Teaching: Young Learner. 2005.

[4] Y, Syafnida \& H. Ardi. 2019. Students' ability in developing generic structure, cohesion and coherence in writing hortatory exposition text. Eighth International Conference on Languages and Arts (ICLA-2019), Advances in Social Science, Education and Humanities Research, volume 46220-223.

[5] L, Jing One Prewriting Activities. 2006. DOI: http://www.linguist.org.cn/doc/su200605/su200605 $\underline{09}$
[6] L, Caroline T. Practical English Language Teaching: Young Learner. 2005

[7] L, Caroline T. Practical English Language Teaching: Young Learner. 2005

[8] Bello, Tom. Improving ESL Learners' Writing Skill. 1997.

DOI: http://www.cal.org/caela/esl_resources/digest/writin $\mathrm{g} / \mathrm{html}$

[9] O, Alice and Ann Hogue. Introduction to Academic Writing, 3rd Ed. United States: Longman. 2007.

[10] Scott, Johnie H. The The cubing technique. 2003. DOI:

http://www.csun.edu/ eduhepas003/cubing.html

[11] Dawson, Melanie. Prewriting: Cubing.: 2001. DOI: http://www.Writing2.richmond.edu/writing/wweb/c ubing.html

[12] Cwiklinski, Agnes. Strategy: Cubing. 2003. DOI: http://www.glencoer.com/sec.teachingtoday/tiparchi ve .phtml/9.htm

[13] Academic Center. Cubing. 2003. DOI: http://www.uhvedu./ac/research/prewriting/cubing.h $\underline{\mathrm{tml}}$

[14] Beacon. Definition and Examples of Prewriting Steps of Brainstorming, Clustering and Questioning. 2003.2 DOI: http://www/beaconlearningcenter.com/documents/1 044 01.pdf

[15] Dibello,ChaterineBuilding Confidence and Competence through Prewriting Activities. 2009. DOI: http://210.59.19.199/mediafile/4170016/fdownload/ 547/452/2009-12-7-16-51-33-452-nf1.pdf

[16] Laneaux, BrittanyPrewriting Activities for Middle School. 2009.2 DOI: http://www.ehow.com/list5794418prewritingactivities-middle-school.html

[17] Peha, Steva. 2002. The Writing Process. DOI: http://www.ttms.org/PDFs/04/WritingProcessV001( Full).pdf 